\title{
Vascular endothelial growth factor in children with cyanotic and acyanotic and congenital heart disease
}

Yasser Baghdady ${ }^{1}$, Yasser Hussein ${ }^{2}$, Mohamed Shehata ${ }^{3}$

${ }^{1}$ Cardiology Department, Faculty of Medicine, Cairo University, Egypt 2Paediatric Department, Faculty of Medicine, Cairo University, Egypt ${ }^{3}$ Clinical Pathology Departments, Faculty of Medicine, Cairo University, Egypt

Submitted: 16 December 2008

Accepted: 15 February 2009

Arch Med Sci 2010; 6, 2: 221-225

DOI: 10.5114/aoms.2010.13899

Copyright $\odot 2010$ Termedia \& Banach

\begin{abstract}
Introduction: Vascular endothelial growth factor is a potent stimulator of angiogenesis. Children with cyanotic congenital heart disease often experience the development of widespread formation of collateral blood vessels, which may represent a form of abnormal angiogenesis resulting in increased morbidity and mortality. We undertook the present study to determine whether children with cyanotic congenital heart disease have elevated serum levels of vascular endothelial growth factor compared to children with acyanotic heart disease. Material and methods: Serum was obtained from 35 children with cyanotic congenital heart disease and 30 children with acyanotic heart disease. Vascular endothelial growth factor levels were measured in the serum of these patients by sandwich enzyme immunoassay.

Results: Vascular endothelial growth factor was significantly elevated in children with cyanotic congenital heart disease compared to children with acyanotic heart disease $(150.3 \pm 48.1$ vs. $85.4 \pm 18.7 \mathrm{pg} / \mathrm{ml}$, respectively, $p<0.001)$. In the cyanotic group, oxygen saturation $\left(\mathrm{SaO}_{2}\right)$ was negatively correlated with VEGF $(r=-0.631, p<0.001)$ while haemoglobin was positively correlated $(r=0.781$, $p=0.007$ ). No significant correlations were found in the acyanotic group.

Conclusions: Children with cyanotic congenital heart disease have elevated systemic levels of vascular endothelial growth factor directly related to the degree of cyanosis $\left(\mathrm{SaO}_{2}\right.$ and haemoglobin levels). These findings suggest that the widespread formation of collateral vessels in these children may be mediated by vascular endothelial growth factor.
\end{abstract}

Key words: vascular endothelial growth factor, congenital heart disease.

\section{Introduction}

Angiogenesis, the formation of new capillary blood vessels, contributes to progression of a variety of diseases, such as tumour dissemination [1], rheumatoid arthritis [2, 3], and diabetic retinopathy [4, 5]. On the other hand, in conditions such as ischaemic cardiovascular disease [6, 7], ulcer healing [8,9], and wound healing [10, 11], it is a physiological response to recover from organ injury because the restoration of blood flow is essential for oxygen and nutrient delivery to the healing site. Remarkable amounts of neovascularization develop in patients with cyanotic congenital heart disease who have low pulmonary blood flow and systemic cyanosis [12, 13]. The neovascularization in these patients has a compensatory role in systemic hypoxia and may be important for organ survival.

\author{
Corresponding author: \\ Ass. Prof. Yasser Baghdady \\ Cardiology Department \\ Faculty of Medicine \\ Cairo University, Egypt \\ E-mail: \\ yasserbaghdady@hotmail.com
}


Abnormal vessel proliferation in these children may take several forms, including systemic-topulmonary collateral arteries [14-17], systemic-topulmonary venous collaterals [18], systemic venous collateral channels after bidirectional cavopulmonary anastomosis [19, 20], and pulmonary arteriovenous malformations [21]. It has been postulated that vascular endothelial growth factor (VEGF) may be responsible for the abnormal vessel proliferation. Several studies have demonstrated that VEGF expression is induced by hypoxia [22-24]. It has also been reported that children with cyanotic congenital heart disease have elevated systemic levels of VEGF [25]. These studies included a small number of patients and need to be validated.

We hypothesized that VEGF may mediate the abnormal angiogenesis which is seen in children with cyanotic congenital heart disease. Thus, the purpose of this study was to determine whether children with cyanotic congenital heart disease have elevated serum levels of VEGF compared to children with acyanotic heart diseases, and also whether the VEGF levels correlate with the degree of cyanosis.

\section{Material and methods}

From September 2007 to March 2008, 65 consecutive children were prospectively entered into the study. Oral consent was obtained from the parents of the children involved in the study. The children's age ranged from 10 months to 10.5 years. The children were divided into two groups: those with cyanotic congenital heart disease (CHD) and those with acyanotic congenital heart diseases. All the patients were recruited from the Paediatric and Cardiology Departments of Cairo University Hospitals.

The first group consisted of 35 children (19 females, 16 males; age range: 10 months-9.8 years) with cyanotic CHD, while the second group included 30 children (16 females, 14 males; aged between 12 months and 10.5 years) with acyanotic congenital heart disease.

All the children were subjected to the following:

- full history and clinical examination, including weight and height; the nutritional status of the patients was assessed by BMI [weight $(\mathrm{kg}) /$ height $\left.\left(\mathrm{m}^{2}\right)\right]$;

- laboratory investigations:

- haemoglobin concentration and haematocrit,

- arterial oxygen saturation: arterial oxygen saturation $\left(\mathrm{SaO}_{2}\right)$ was analysed in blood samples drawn from the peripheral vessels,

- level of VEGF in serum: blood samples for VEGF analyses were withdrawn by standard venipuncture and were centrifuged for $10 \mathrm{~min}$ at $5000 \mathrm{rpm}$ and then serum samples were stored at $-20^{\circ} \mathrm{C}$ until the time of analysis; serum VEGF level was measured with sandwich enzyme immunoassay using commercially available kits (Human VEGF, Cytimmune Sciences Inc., Rockville, MD, USA), - other investigations included kidney function, complete blood picture and prothrombin time and concentration;

- chest X-ray: PA and lateral views;

- twelve-lead electrocardiogram;

- echocardiography: using a Sonos 5500 ultrasound system (HP Hewlett Packard), with a $5 \mathrm{MHz}$ transducer for children. M-mode and 2-dimensional examinations were performed from the standard subcostal, parasternal and apical approaches; Doppler (pulsed wave and continuous wave) and colour Doppler mapping were also used to reach the diagnosis;

- cardiac catheterization: using a Philips biplane cardiac catheterization laboratory:

- this was performed in:

- patients with pulmonary atresia: mainly to determine the origin and distribution of collaterals,

- patients with tetralogy of Fallot: to define the coronary arteries and to determine the left ventricular diastolic volume and index; also to determine the origin and distribution of collaterals.

Both right and left sided cardiac catheterization was performed and pressure was measured in all chambers and from the pulmonary artery and pulmonary veins (wedge pressure). Saturation in all the chambers was also performed to detect shunts. Clinical diagnoses in both groups are listed in Table I.

Exclusion criteria included:

- patients with acute illness;

- patients who were critically ill, including those with moderate to severe malnutrition, according to the growth indices (Table II);

- patients scheduled for surgery during the withdrawal of blood samples;

- patients with pulmonary hypertension.

Data were analysed by the Statistics Package for Social Sciences Statistical Software (SPSS) 11.0. All results were expressed as the mean value \pm standard deviation. Student's t-test was used for comparisons between the two groups. The correlations between the groups were assessed by Pearson correlation. A value of $p<0.05$ was interpreted as indicating statistical significance.

\section{Results}

As regards the general characteristics of patients, no significant difference was found between the groups for age ( $p=0.652)$, body weight or height (Table II). Nutritional status of the two groups was assessed by body weight, height and BMI. Body mass index levels were within the normal range in 
Table I. Diagnoses in cyanotic and acyanotic groups

\begin{tabular}{|lccc|}
\hline Group & Diagnosis & Number of patients & Female/male \\
\hline Cyanotic group I $(n=35)$ & Tetralogy of Fallot & 20 & $19 / 16$ \\
\cline { 2 - 3 } & Double outlet RV & 6 & \\
\cline { 2 - 3 } & TGA + VSD & 7 \\
\hline Acyanotic group II $(n=30)$ & PA + VSD & 2 & $16 / 14$ \\
\cline { 2 - 3 } & VSD & 18 & \\
\hline & ASD & 8 & \\
\hline
\end{tabular}

$R V$ - right ventricle, TGA - transposition of great arteries, VSD - ventricular septal defect, PA - pulmonary atresia, ASD - atrial septal defect, $P D A$ - patent ductus arteriosus

Table II. Indices used to determine the nutritional status of the children included in the study [26]

\begin{tabular}{|llccc|}
\hline Nutritional status & Weight/age & Height/age & Weight/height & $\%$ IBW \\
\hline Wasting & Normal or low & Normal & $<5^{\text {th }}$ percentile & $<85-90 \%$ \\
\hline Stunting & $<5^{\text {th }}$ percentile & $<5^{\text {th }}$ percentile & Normal & Normal \\
\hline Mild malnutrition & Normal or low & Normal & $<5^{\text {th }}$ percentile & $81-90 \%$ \\
\hline Moderate malnutrition & Normal or low & Normal & $<5^{\text {th }}$ percentile & $70-80 \%$ \\
\hline Kwashiorkor & Normal or low & Normal or low & Normal (oedema) & Normal \\
\hline
\end{tabular}

IBW - ideal body weight

the cyanotic group and acyanotic group, showing absence of moderate or severe malnutrition in both groups; however, BMI levels were significantly lower in the cyanotic as compared to the acyanotic group $(p<0.001)$ (Table III).

Serum VEGF was measured in all subjects (Table IV). The mean VEGF level was significantly higher in the cyanotic group as compared to the acyanotic group $(150.3 \pm 48.1 \mathrm{vs} .85 .4 \pm 18.7 \mathrm{pg} / \mathrm{ml}$, respectively, $p<0.001)$.

$\mathrm{SaO}_{2}$ values were significantly lower in the cyanotic group than those in the acyanotic group $(80.4 \pm 2.4$ and $97.5 \pm 1.9$, respectively; $p<0.001)$. The $\mathrm{SaO}_{2}$ values were compared with the VEGF level in each group. In the cyanotic group, $\mathrm{SaO}_{2}$ was negatively correlated with VEGF ( $r=-0.631$, $p<0.001)$. No significant correlation was noted between VEGF and $\mathrm{SaO}_{2}$ in the acyanotic group (Table IV).

Table III. Demographic data in cyanotic and acyanotic groups

\begin{tabular}{|lccc|}
\hline & Cyanotic & Acyanotic & $P$ \\
\hline Age [year] & $3.1 \pm 1.6$ & $3 \pm 1.7$ & 0.652 \\
\hline Body weight $[\mathrm{kg}]$ & $13.5 \pm 4.1$ & $15.1 \pm 2.5$ & 0.327 \\
\hline Height $[\mathrm{cm}]$ & $93.1 \pm 14.6$ & $95.2 \pm 12.1$ & 0.738 \\
\hline BMI $\left[\mathrm{kg} / \mathrm{m}^{2}\right]$ & $14.3 \pm 0.4$ & $16.7 \pm 0.7$ & $<0.001^{\star}$ \\
\hline
\end{tabular}

$B M I$ - body mass index, data are mean \pm standard deviation *Indicates significant difference
Haemoglobin levels were significantly different between the groups $(13.5 \pm 1.7$ and $11.81 \pm 0.97$, respectively; $p<0.001)$. Haemoglobin levels were compared with VEGF in each group. Haemoglobin was positively correlated $(r=0.781, p=0.007)$ with VEGF in the cyanotic group.

No correlations were noted between the VEGF, haemoglobin and $\mathrm{SaO}_{2}$ levels in the acyanotic group (Table V).

\section{Discussion}

The present study demonstrated that VEGF level was significantly elevated in children with cyanotic heart disease compared to children with acyanotic

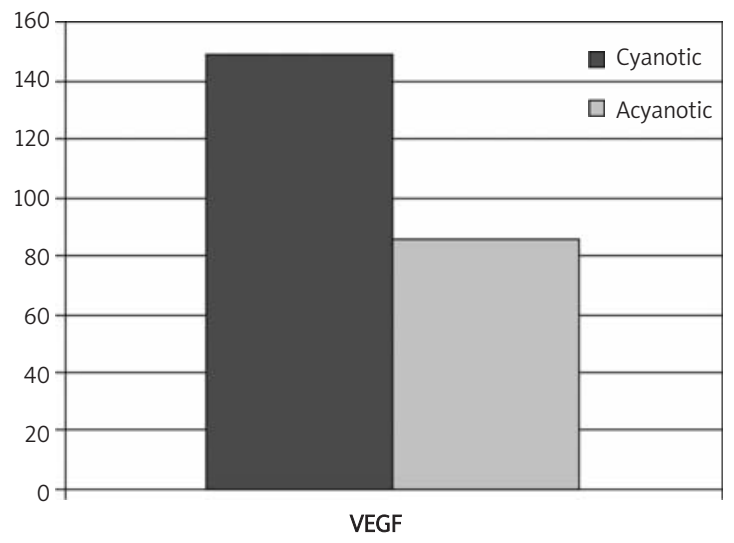

Figure 1. Vacular endothelial growth factor levels in cyanotic and acyanotic groups $(p<0.001)$ 
Table IV. Vascular endothelial growth factor, haemoglobin and arterial oxygen saturation in cyanotic and acyanotic groups

\begin{tabular}{|lccc|}
\hline & Cyanotic & Acyanotic & Value of $p$ \\
\hline VEGF $[\mathrm{pg} / \mathrm{ml}]$ & $150.3 \pm 48.1$ & $85.4 \pm 18.7$ & $<0.001^{*}$ \\
\hline Haemoglobin $[\mathrm{g} / \mathrm{l}]$ & $13.5 \pm 1.7$ & $11.81 \pm 0.97$ & $<0.001^{*}$ \\
\hline $\mathrm{SaO}_{2}[\%]$ & $80.4 \pm 2.4$ & $97.5 \pm 1.9$ & $<0.001^{*}$ \\
\hline
\end{tabular}

VEGF - vascular endothelial growth factor, $\mathrm{SaO}_{2}$ - arterial oxygen saturation, data are mean \pm standard deviation

*Indicates significant difference

heart disease. These results are similar to previous studies [25, 32]. This elevated level of VEGF in the cyanotic group can be explained by the hypoxia, which is a strong stimulus for angiogenesis and leads to upregulation of VEGF. The lack of correlation, in the acyanotic group, between the VEGF level and the oxygen saturation or the haemoglobin level suggests that the main stimulus for VEGF elevation was the cyanosis present (low oxygen saturation and elevated haemoglobin levels).

The importance of neovascular formation in children with cyanotic heart disease is that it increases morbidity and mortality. An example of this is the development of aortopulmonary collateral arteries associated with pulmonary atresia. This may cause a number of problems, including significant left to right shunting, progressive obliteration after unifocalization procedures, and pulmonary "steal" from systemic blood flow during cardiopulmonary bypass. The management of children with cyanotic congenital heart disease may be complicated by the development of these vascular lesions and may require interventional cardiac catheterization or surgical treatment [25].

Vascular endothelial growth factor is a potent mitogen acting specifically on vascular endothelial cells, and is known to play a role in angiogenesis in widely divergent circumstances, such as embryonic development [27], wound healing [9-11], tumour growth [28], rheumatoid arthritis [2, 3, 29], and ischaemic retinopathy [30]. Vascular endothelial growth factor has been demonstrated to induce angiogenesis, endothelial cell proliferation, and migration, thereby promoting blood vessel growth. Recent studies have demonstrated that angiogenesis, facilitated by administration of angiogenic growth factors as in recombinant protein therapy or gene transfer, may be augmented in animal models of myocardial ischaemia [31]. Therapeutic angiogenesis with VEGF was recently performed in order to reduce the unfavourable tissue effects caused by ischaemia [32].

The present study represents a preliminary attempt to identify factors that may have an
Table V. Correlation coefficients in cyanotic and acyanotic groups

\begin{tabular}{|lcccc|}
\hline & \multicolumn{2}{c}{ Cyanotic VEGF } & \multicolumn{2}{c|}{ Acyanotic VEGF } \\
\cline { 2 - 5 } & $R$ & $p$ & $R$ & $p$ \\
\hline Haemoglobin & 0.781 & 0.007 & 0.27 & 0.217 \\
\hline $\mathrm{SaO}_{2}[\%]$ & -0.631 & $<0.001^{*}$ & -0.321 & 0.347 \\
\hline
\end{tabular}

$V E G F$ - vascular endothelial growth factor, $\mathrm{SaO}_{2}$ - arterial oxygen saturation

*Indicates significant correlation

impact on manifestations of cyanotic congenital heart disease. Vascular endothelial growth factor appears to be systemically elevated in patients with chronic cyanosis and may contribute to the formation of extensive collateral vessels that sometimes develop in these children. Issues related to the exact origin of these factors are not specifically answered by this study. However, these findings may have broader implications regarding the pathophysiological features of cyanotic heart disease, while further study of affected children may aid in understanding the control mechanisms of angiogenesis.

Limitations: a limitation of this study was the broad variation in circulatory dynamics within the cyanotic group. The cyanotic group consisted of patients with various congenital heart diseases, such as tetralogy of Fallot causing decreased pulmonary blood flow, or a double outlet right ventricle causing increased pulmonary blood flow. Variability of the underlying haemodynamics and anatomy of the cyanotic group may make consistent analysis impossible. Vascular endothelial growth factor elevation may depend not only on systemic oxygen saturation but also on other factors, such as cytokines. More detailed studies are required to resolve this question.

Also, VEGF elevation may be related to the function of time. It was difficult for us to standardize an age limit for our cohort of patients (e.g. 2-year old children with CHD). Also the normal level of VEGF according to age is still uncertain [33].

Our study was also limited by the number of patients and the lack of visualization of the arteriovenous connections within the cyanotic group.

In conclusion, children with cyanotic heart disease have elevated levels of VEGF (compared to children with acyanotic heart disease) and this elevation is directly correlated with the haemoglobin concentration and inversely correlated with the level of hypoxia. These findings suggest that the widespread formation of collateral vessels in these children may be mediated by vascular endothelial growth factor. 


\section{References}

1. Carmeliet $P$, Jain RK. Angiogenesis in cancer and other diseases. Nature 2000; 407: 249-57.

2. Nagashima M, Tanaka H, Takahashi $\mathrm{H}$, et al. Study of the mechanism involved in angiogenesis and synovial cell proliferation in human synovial tissues of patients with rheumatoid arthritis using SCID mice. Lab Invest 2002; 82: 981-8.

3. Szekanecz A, Szegedi G, Koch AE. Angiogenesis in rheumatoid arthritis: pathogenic and clinical significance. J Investig Med 1998; 46: 27-41.

4. Aiello LP, Avery RL, Arrigg PG, et al. Vascular endothelial growth factor in ocular fluid of patients with diabetic retinopathy and other retinal disorders. N Engl J Med 1994; 331: 1480-7.

5. Frank RN. Diabetic retinopathy. N Engl J Med 2004; 350: 48-58.

6. Losordo DW, Dimmeler S. Therapeutic angiogenesis and vasculogenesis for ischemic disease. Part I: angiogenic cytokines. Circulation 2004; 109: 2487-91.

7. Ware JA, Simons M. Angiogenesis in ischemic heart disease. Nat Med 1997; 3: 158-64.

8. Jones MK, Wang $\mathrm{H}$, Peskar BM, et al. Inhibition of angiogenesis by nonsteroidal anti-inflammatory drugs: insight into mechanisms and implications for cancer growth and ulcer healing. Nat Med 1999; 5: 1418-23.

9. Ma L, del Soldato P, Wallace JL. Divergent effects of new cyclooxygenase inhibitors on gastric ulcer healing: shifting the angiogenic balance. Proc Natl Acad Sci U S A 2002; 99: $13243-7$.

10. Jacobi J, Tam BY, Sundram U, et al. Discordant effects of a soluble VEGF receptor on wound healing and angiogenesis. Gene Ther 2004; 11: 302-9.

11. Knighton DR, Silver IA, Hunt TK. Regulation of woundhealing angiogenesis - effect of oxygen gradients and inspired oxygen concentration. Surgery 1981; 90: 262-70.

12. DuncanBW, Kneebone JM, Chi EY, et al. A detailed histologic analysis of pulmonary arteriovenous malformations in children with cyanotic congenital heart disease. J Thorac Cardiovasc Surg 1999; 117: 931-8.

13. Rossi RN, Hislop A, Anderson RH, Martins FM, Cook AC. Systemic-to-pulmonary blood supply in tetralogy of Fallot with pulmonary atresia. Cardiol Young 2002; 12: 373-88.

14. Ichikawa $H$, Yagihara $T$, Kishimoto $H$, et al. Extent of aortopulmonary collateral blood flow as a risk factor for Fontan operations. Ann Thorac Surg 1995; 59: 433-7.

15. Kanter KR, Vincent RN, Raviele AA. Importance of acquired systemic-to-pulmonary collaterals in the Fontan operation. Ann Thorac Surg 1999; 68: 969-75.

16. McElhinney DB, Reddy VM, Tworetzky W, Petrossian E, Hanley FL, Moore P. Incidence and implications of systemic to pulmonary collaterals after bi-directional cavopulmonary anastomosis. Ann Thorac Surg 2000; 69: 1222-8.

17. Spicer RL, Uzark KC, Moore JW, Mainwaring RD, Lamberti J. Aortopulmoanry collateral vessels and prolonged pleural effusions after modified Fontan procedures. Am Heart J 1996; 131: 1164-8.

18. Clapp S, Morrow WR. Development of superior vena cava to pulmonary vein fistulae following modified Fontan operation: case report of a rare anomaly and embolization therapy. Pediatr Cardiol 1998; 19: 363-5.

19. Gatzoulis MA, Shinebourne EA, Redington AN, Rigby ML, Ho SY, Shore DF. Increasing cyanosis early after cavopulmonary connection caused by abnormal systemic venous channels. Br Heart J 1995; 73: 182-6.
20. McElhinney DB, Reddy VM, Hanley FL, Moore P. Systemic venous collateral channels causing desaturation after bidirectional cavopulmonary anastomosis: evaluation and management. J Am Coll Cardiol 1997; 30: 817-24.

21. Srivastava D, Preminger T, Lock JE, et al. Hepatic venous blood and the development of pulmonary arteriovenous malformations in congenital heart disease. Circulation 1995; 92: 1217-22.

22. Asano M, Kaneoka K, Nomura T, et al. Increase in serum vascular endothelial growth factor levels during altitude training. Acta Physiol Scand 1998; 162: 455-9.

23. Breier G, Albrecht U, Sterrer S, Risau W. Expression of vascular endothelial growth factor during embryonic angiogenesis and endothelial cell differentiation. Development 1992; 114: 521-32.

24. Brogi E, Wu T, Namiki A, Isner JM. Indirect angiogenic cytokines upregulate VEGF and bFGF gene expression in vascular smooth muscle cells, whereas hypoxia upregulates VEGF expression only. Circulation 1994; 90: 649-52.

25. Starnes SL, Duncan BW, Kneebone JM, et al. Vascular endothelial growth factor and basic fibroblast growth factor in children with cyanotic congenital heart disease. J Thorac Cardiovasc Surg 2000; 119: 534-9.

26. Wilmore D. The Metablic Management of the Critically III. New York. Plenum Publishing, 1977. Revised in Walker W, Watkins J [eds]: Nutrition in Pediatrics: Basic Science and Clinical Application. Boston, Little, Brown, 1985.

27. Feucht $M$, Christ B, Wilting J. VEGF induces cardiovascular malformation and embryonic lethality. Am J Pathol 1997; 151: 1407-16.

28. Galligioni E, Ferro A. Angiogenesis and antiangiogenic agents in non-small cell lung cancer. Lung Cancer 2001; 34 (Suppl 4): S3-7.

29. Ballara SC, Miotla JM, Paleolog EM. New vessels, new approaches: angiogenesis as a therapeutic target in musculoskeletal disorders. Int J Exp Pathol 1999; 80: 235-50.

30. Lu M, Adamis AP. Vascular endothelial growth factor gene regulation and action in diabetic retinopathy. Ophthalmol Clin North Am 2002; 15: 69-79.

31. Takeshita S, Pu L-Q, Zheng L, et al. Vascular endotherial growth factor induces dose-dependent revascularization in a rabbit model of persistent limb ischemia. Circulation 1994; 90: II228-34.

32. Schumacher B, Pecher P, von Specht BU, Stegmann T. Induction of neoangiogenesis in ischemic myocardium by human growth factors: first clinical results of a new treatment of coronary heart disease. Circulation 1998; 97 : 645-50.

33. Ootaki Y, Yamaguchi M, Yoshimura N, et al. Vascular endothelial growth factor in children with congenital heart disease. Ann Thorac Surg 2003; 75: 1523-6. 